\title{
Jaula de vidro
}

[ Glass cage

\section{Silvia Viana ${ }^{\mathrm{I}}$}

RESUmo Como novo formato da indústria cultural, os reality shows se tornaram objeto de interesse acadêmico na última década. Das variadas análises a seu respeito, as mais comuns são aquelas voltadas para o interesse gerado em um público ávido pelo obsceno, pelo perverso ou, em sentido lacaniano, por um "acesso imediato ao Real”. Na contramão dessa perspectiva, o presente trabalho busca desenvolver a hipótese segundo a qual tais programas apresentam, em sua forma engessada, não obstante a multiplicação de conteúdos, nossa própria fantasia social. Ou seja, não se trata de uma configuração barrada da cena social, mas daquilo mesmo que a sustenta: nossa reprodução no mundo de trabalho, organizado segundo a acumulação capitalista flexível. O presente ensaio não é uma síntese, mas a reapresentação de algumas das conclusões às quais cheguei em minha pesquisa de doutorado, a respeito de reality shows, realizada junto ao Departamento de Sociologia da USP. - PALAVRAS-CHAVE Reality

Recebido em 24 de março de 2014

Aprovado em 30 de junho de 2014 show, ideologia, trabalho, sofrimento, indiferença. - ABSTRACT As new format of the cultural industry, reality shows have become the subject of academic interest in the last decade. Among the various analyzes about it, the most common are those related to the interest generated on a public eager for the obscene, or the perverse, in the Lacanian sense, for an "immediate access to the Real." In opposition to this perspective, this paper seeks to develop the hypothesis that such programs present, in a plastered form, despite the proliferation of contents, our own social fantasy. i.e., it doesn't shows a barred social scene, but this scene itself: the production world, organized according to capitalist flexible accumulation. This essay is not an abridgement, but a new presentation of some conclusions of my doctoral research on reality shows, done at the Department of Sociology of the University of São Paulo. • KEYwords Reality show, ideology, work, suffering, indifference.

VIANA, Silvia. Jaula de vidro. Revista do Instituto de Estudos Brasileiros, Brasil, n. 60, p. 9I-I09, abr. 2015. DoI: http://dx.doi.org/Io.II606/issn.23I6-90IX.voi6op9I-I09

I Fundação Getúlio Vargas (FGV, São Paulo, SP, Brasil). 
Em “Esfinge"2, uma história curta, narrada em quadrinhos, Laerte mostra, primeiro, a tela do computador, depois, o homem diante dela. Levanta-se, veste o casaco. Entra no elevador. No carro, olha para trás, para dar a ré. O carro azul aparece preso no trânsito, depois, na garagem cercada. Entra no elevador. Em casa, o beijo na esposa: “amor"; “amor". Senta-se para assistir à TV. Voltado para a tela, pergunta: "Amor, você viu aquele negócio da conta do celular?”. De uma sombra preta, ao lado da poltrona, aparece a resposta: "pergunta errada”. O homem solta um grito de terror.

Mesmo diante do desespero da esposa, que anseia levá-lo ao hospital, ele permanece sentado, pensativo, observando o espaço da mão que agora lhe falta, pois não há ferida aberta, sangue ou dor, somente a questão a respeito do ser que o amputara: "parecia uma... esfinge". Ainda segurando o controle remoto com a mão que restou, decide-se: "esquece". Mantém-se irredutível mesmo quando, depois de dormir, acordar, mijar, comer, voltar ao escritório, dar bons dias e até amanhãs, tem, na garagem do escritório, o pé direito devorado, graças a outra pergunta errada: “será que cresce de novo?”.Apenas face à exasperação de sua mulher e filho, abandona a calma sobriedade e grita: "Por que não me deixam em paz?”. “Pergunta... errada”. O ser se dá a ver, emoldurado pela janela, completo: asas, seios fartos, garras de leão, dentes afiados, olhos vermelhos. Arranca a perna que sobrava incólume e sai. Para o homem, buscar ajuda seria descabido, pensariam que ele não passa de um inválido querendo fazer troça; então, "deixa pra lá". Cama, privada, arrasta-se pela rua, agora vai de táxi. “Por que comigo?”."Pergunta errada”" na calçada, o outro braço é devorado. Elevador, escrivaninha, com o mouse na boca realiza seu trabalho. Elevador, táxi, casa. Um bilhete anuncia que fora deixado pela família. Sofá, TV, controle remoto na boca, cama: “porque não apaguei a luz?”, "pergunta errada”. Na manhã seguinte, a parte superior do tronco e a cabeça rastejam até o banheiro, tentam a privada, permanecem prostrados no chão: “Por que?... Porque caralho eu tenho que ir para o escritório?”, a sombra preta com olhos vermelhos desponta à porta: “Pergunta certa. Quer a resposta?”.

"Não".

2 COUTINHO, Laerte, Esfinge. Piauí, n. 5, fev. 2007. Disponível em: 〈http://goo.gl/KGyHVh〉. Acesso em: I2 dez. 2014 . 
Correr pela rua dá uma impressão de pavor. [...] A postura da cabeça, tentando manter-se erguida, é a de alguém que se afoga, o rosto tenso assemelha-se à careta de dor. Ela tem que olhar para a frente, quase não consegue olhar para trás sem tropeçar, como se seu perseguidor - cuja visão deixa-a gelada de horror - já respirasse em sua nuca. ${ }^{3}$

É muito comum se imaginar que os problemas da humanidade são essencialmente os mesmos e o que varia são as respostas que as diferentes sociedades, na história, no espaço e no tempo, dão às questões. Mas as questões são essencialmente as mesmas, nós somos todos humanos etc. Não é verdade, as questões não são necessariamente as mesmas, ao contrário, o que justamente distingue as culturas são o tipo de pergunta que elas fazem, as questões que elas se colocam e são as questões que se diferem, muito mais do que as respostas. O senso de estranheza, o sentido de não estar no lugar que você conhece, estar fora de casa, está justamente no fato de que as pessoas não estão preocupadas com as mesmas coisas que você. Percepção súbita de que as pessoas não estão falando da mesma coisa que você [...]. E todo o problema do antropólogo é descobrir quais são as perguntas, afinal, que a vida daquelas pessoas está respondendo, a que perguntas a vida delas é uma resposta. ${ }^{4}$

Sendo assim, a quais questões a vida em nossa sociedade busca responder?

Pergunta difícil, talvez nem tanto por sua amplitude filosófica quanto pela percepção prática da inexistência do sujeito em questão: a sociedade. Pois os seis sentidos sabem, e a voz do mundo não os deixa mentir, sermos átomos submersos na concorrência de mercado, ainda que o pensamento possa resistir ao apelo da propaganda que impele à "batalha" cotidiana. Daí a questão em si parecer estranha: sua formulação nos carrega necessariamente para fora de casa - essa, um lugar a partir do qual não se pode falar, já que não há teto ou piso comuns, nem mesmo os ultrapassados salariais. Não obstante, cá entre nós, talvez nunca tenha havido tamanha uniformidade de vida, de "partículas minúsculas, eternas e indivisíveis, que se combinam e desagregam movidas por forças mecânicas da natureza”s que somos.

E é precisamente às forças da natureza que devemos essa condição ímpar, ou pelo menos é assim que reza a cosmogonia que nos é própria. Já escutamos infinitas vezes a "fatalidade meteorológica"6 à qual devemos nossos dias. Segundo ela, a revolução organizacional e tecnológica acirrou a concorrência entre as empresas; essas precisam tornar-se mais produtivas se não quiserem desaparecer. Para isso incrementam a tecnologia e o trabalho informacional, terceirizam setores menos lucrativos, dispensam mão de obra cujo trabalho repetitivo pode ser substituído por robôs, lançam mão de formas de contrato

3 ADORNO, Theodor W. Minima Moralia. São Paulo, Ática, I992, p. I42.

4 VIVEIROS DE CASTRO, Eduardo. A morte como quase acontecimento. Conferência proferida na CPFL, Campinas, 2008. Disponível em: 〈http://goo.gl/QFasUK >. Acesso em: I6 ago. 2011.

5 Átomo. In: Dicionário Eletrônico Houaiss da Língua Portuguesa 3.o. Rio de Janeiro, Objetiva, 2009.

6 A respeito das imagens da dissolução social, forjadas após o "triunfo neoliberal”, ver: ARANTES, Paulo. O pensamento único e o marxista distraído. In: Zero à Esquerda. São Paulo, Conrad, 2004; A fratura brasileira do mundo. In: .Zero à Esquerda. São Paulo, Conrad, 2004. 
de trabalho menos onerosas (como o trabalho temporário) e submetem sua produção à valorização financeira. Restam ao Estado dois problemas: dar suporte à competitividade de suas empresas para que o país não seja engolido pela concorrência mundial e evitar que os excluídos se tornem excessivos demais. Há uma resposta para ambos os problemas: desregulamentação. Por um lado, a desregulamentação financeira, que aumenta o fluxo de capitais, por outro, a desregulamentação do trabalho para atrair mais capital e, com isso, aumentar a oferta de empregos. Junto às privatizações, que igualmente dinamizam a economia, as desregulamentações diminuem a ingerência e o peso do Estado no mercado. O problema da competitividade está resolvido; o dos excluídos, apenas parcialmente. Cabe, então, a cada um, a tarefa e a responsabilidade da autorreciclagem, senão...

Como todo discurso capitalista, seu sintoma é o trabalho. Francisco de Oliveira7 separa o joio do trigo ao mostrar que a perda da dimensão pública do trabalho não é o mesmo que sua rarefação; pelo contrário, a reestruturação que aparece como descarte possibilita e oculta o movimento real de uma ampliação inaudita de suor. À incorporação de novas camadas populacionais ao mercado de trabalho-em especial, mulheres jovens ${ }^{8}$ - soma-se a assimilação das profissões liberais ao assalariamento. À precarização do trabalho, que multiplica a jornada a ponto de tornar-se incomensurável, soma-se sua intensificação? Mas é à miragem das pessoas-capital que devemos o desaparecimento de qualquer limite que poderia se impor entre o reino da produção e qualquer outra coisa que não o seja: Lazer? Consumo? Viajem? Hobby? Amizade? Sonho? Tudo pode, e deve, ser meio para nossa própria valorização, para que nosso nível de "empregabilidade” não decresça abaixo do nível aceitável. E, por aqui, o oásis nunca chega, a sede não se sacia, a produção jamais, e em espaço algum, cessa ${ }^{\text {Io }}$.

Temos, assim, um mito de origem que é também, ao mesmo tempo, uma condição sem remissão. Não há imagens disponíveis para qualquer forma de salvação quando o trabalho, que antes era vendido como mercadoria útil, aparece como o quase nada que nos separa da lata de lixo. E, no entanto, por isso mesmo, se torna tudo. Nas palavras de um diretor de recursos humanos, entrevistado por Oswaldo Lópes-Ruiz: "Tem que estar sempre correndo atrás. É uma escada rolante que desce: para vocêficar no degrau, você tem que andar, senão ela te puxa. A escada é a empresa. Antigamente a escada era fixa: o cara subia um degrau,

7 OLIVEIRA, Francisco de. Passagem na Neblina. In: GENOINO, José \& STEDILE, João Pedro. Classes Sociais em Mudança e a Luta pelo Socialismo. Coleção Socialismo Em Discussão. São Paulo, Fundação Perseu Abramo, 2000, p. I8.

8 BERNARDO, João. Trabalhadores: Classe ou Fragmentos? 2007 Mayday - O Precariado Rebela-se, 2 abr. 2007. Disponível em: 〈http://goo.gl/Jdwgbo〉. Acesso em: 20 abr. $20 I I$.

9 Utilizo a expressão “intensidade do trabalho" no sentido empregado por Sadi Dal Rosso. Não se trata de incremento produtivo, apesar de poder resultar em maior produtividade, mas de um maior engajamento do trabalhador em sua tarefa: "A intensidade é mais que esforço físico, pois envolve todas as capacidades do trabalhador, sejam as de seu corpo, a acuidade de sua mente, a afetividade despendida ou os saberes adquiridos através do tempo ou transmitidos pelo processo de socialização”. ROSSO, Sadi Dal. Mais Trabalho! A Intensificação do Labor na Sociedade Contemporânea. São Paulo, Boitempo, 2008, p. 21.

Io A respeito da teoria do capital humano, ver: LÓPEZ-RUIZ, Oswaldo Javier. O Ethos dos Executivos das Transnacionais e o Espírito do Capitalismo. Tese de Doutorado em Sociologia, Campinas, Unicamp, 2004 , p. 3Io. 
subia outro degrau, podia até descansar um pouquinho... trocaram a escada"ז. Eis o ponto: corremos atrás de que, se o objetivo não é mais que a própria permanência? Quando até mesmo os assim chamados "vencedores", especialmente na figura do empreendedor bem-sucedido, são aclamados por nada mais que sua capacidade de autoconservação ${ }^{\mathrm{I2}}$, o topo, tanto quanto o descanso, estão excluídos do campo do possível. A premência de alcançar o que está à frente é sempre também a fuga febril de uma ameaça que se aproxima por trás ou, como nos ensina um "educador corporativo": "evoluir é fundamental para sobreviver na carreira", afinal "quem não evolui desaparece"זз.

Sob o risco de tornarmo-nos fantasmas, de sermos atirados para esse além presente, não obstante desconhecido, nos é vetada a possibilidade de parar, pois a "atrofia da disposição", a "inépcia moral", a "invalidez da vontade", são mais que erro; como se pode apreender dos termos usados pelo mesmo "educador", são pecado. Por isso, cabe a esse que ora nos ensina o que já devemos saber de berço, mostrar o caminho das pedras: sigamos o exemplo do tenente Rowanque, na guerra Hispano-americana, foi encarregado de levar uma mensagem ao general cubano aliado dos Estados Unidos; ele "passou fome e frio, quase foi preso, mas não esmoreceu nunca e finalmente conseguiu entregar a mensagem ao general Garcia”. O valor da história, contudo, não reside naquilo que se logrou mediante tal feito, mas apenas no fato de ter sido feito: "o texto da mensagem não importa, o que valeu foi o ato de entregá-la”. Tampouco interessa o móbile da ação: "a história é um pouco criticada porque sugere obediência cega, submissão à autoridade, mas também é uma homenagem ao comprometimento". Por isso, ao tenente Rowan, àquele que faz, não importando o que, como ou para que, devem ser erguidas "estátuas de bronze" "T4. Eis, então, a moral da história, a tal "mensagem aos acomodados": "quem se acomoda, no mínimo, para de avançar na carreira, abrindo espaço para quem vem atrás” o imperativo: "Não desista de nada"ז6.

II Idem, p. 3Io. Grifo meu.

I2 Como quando a CEO da Xerox afirma com orgulho ter buscado inspiração para a reestruturação de sua empresa no livro Endurance, "que mostra como há mais de um século o desbravador inglês Ernest Shackleton livrou-se de uma tragédia que liquidou sua embarcação na Antártida, comendo pinguim e foca, à deriva num bloco de gelo" (Mano, Cristiane. Chega de Ser Boazinha. Exame, ano 44, n. 20, 3 nov. 20Io). Já uma consultora de grandes empresas no Brasil escreveu um livro cujo título já diz muito: "Sobreviver: Instinto de Vencedor"; ela se inspirou em pessoas como "o modelo Ranimiro Lotufo, que perdeu a perna direita num acidente”, e "Edith Eva Eger, sobrevivente do campo de concentração nazista de Auschwitz”. (Só os Flexíveis Sobrevivem" - entrevista com Claudia Rieken. Você S/A, ed. IO4, Io fev. 2007). O ar puro que respiram os "vencedores" só parece grande coisa porque sob sua cabeça está pintado um mar revolto.

I3 MUSSAK, Eugênio. Evoluir é Fundamental para Sobreviver na Carreira. Você S/A, n. I79, I jan. 2013.

I4 Idem. Mensagem aos Acomodados. Você S/A, n. I54, I abr. $201 \mathrm{I}$.

I5 Idem. Está na Hora de Mudar. Você S/A, n. II6, I fev. 2008.

I6 Idem. Quando Eu quase Desisti”. Você S/A, n. I6o, I out. $201 \mathrm{II}$. 
Todo dia é véspera do fim para alguém. ${ }^{\text {T7 }}$

Pedro Bial

Uma das maiores dificuldades em se lecionar a questão da modernidade atualmente é fazer entender à nova geração que, há não mais de um século, a promessa de liberdade por ela legada era tão fundamental que se arriscava a vida em nome de sua realização. A ideia soa ridícula para aqueles que tripudiam até mesmo da já esquálida, hoje moribunda, esperança de bem-estar e ascensão social ${ }^{\mathrm{I}}$. É como se, sob regime de acumulação fordista, o mundo afirmasse: “O que está dado é bom e é bom porque está dado”, e agora não deixasse de repetir: "A vida é dura, adapte-se a isso e busque sobreviver".

Sendo assim, não é de se estranhar que a mercadoria cultural própria aos tempos que correm seja o reality show: a Lei que rege cada um dos episódios de cada um dos inúmeros programas é a da sobrevivência ante o descarte inelutável. Como afirma o diretor do mais famoso entre eles: "Big Brother não é cultura, não é um programa que propõe debates. É um jogo cruel, em que o público decide quem sai. Ele dá o poder de o cara que está em casa ir matando pessoas, cortando cabeças. Não é um jogo de quem ganha. Para o cara de casa, é um jogo de quem você elimina”ঙ̣. Daí a estrela do show, seu verdadeiro protagonista, ser o "paredão"2o, procedimento no qual dois, três ou até quatro participantes são levados à votação da audiência. Àquele que for dedicado o maior número de ligações telefônicas, cliques na internet e mensagens via SMS é destinada a exclusão, sem direito a apelação. Tudo o que se passa na tal "casa mais vigiada do Brasil" revoluteia em torno desse vórtice, pois aqueles que tiveram a infelicidade de subir ao cadafalso devem sua sina aos colegas de clausura, encarregados, no interregno entre as execuções, do trabalho sujo que é a escolha dos outros para a eliminação. Uma pré-seleção para a seleção, que ocorre em um minúsculo

I7 Pedro Bial, apresentador do programa Big Brother Brasil, da TV Globo, ao anunciar a eliminação de um participante da I4 ${ }^{\mathrm{a}}$ edição.

I8 Nota para investigação: a apreensão da sociologia que leciono para alunos da administração de empresas subitamente ganhou novo interesse após Junho de 20I3. Algo na fantasia social hobbesiana que até então se mantinha incólume foi arranhado? Cedo para dizer. Fato é que já não é necessária uma ginástica explicativa para fazer os alunos entenderem o que significa correr Risco - com maiúscula pois, evidentemente, não falo da figura ideológica do risco, propalada como elemento organizador do universo, ao mesmo tempo virtude de mercado e mal absoluto contra o qual medidas securitárias de exceção nunca serão o suficiente - e, talvez por isso mesmo, seja possível recuperarmos a dimensão do ser cedo, que já não é o tarde demais.

I9 “'Big Brother' não é cultura, é um jogo cruel”, diz Boninho. Folha de S. Paulo, 2I mar. 2010.

$20 \mathrm{O}$ termo, que remete às execuções por fuzilamento em Cuba, foi reempregado por um participante da primeira edição do programa global no lugar do original “dia de eliminação”. A expressão aderiu com tanta força ao princípio ao qual remete que até em programas concorrentes é difícil fixar outra; nesses, volta e meia ocorre uma apropriação involuntária. A expressão aparece, por exemplo, em legendas de reality shows americanos transmitidos no Brasil, tais como Hell's Kitchen (Transmitido atualmente no Brasil pelo canal a cabo TLC) e Top Chef (canal Sony). 
quarto escuro, chamado pela novilíngua do programa "confessionário", no qual a eleição do colega vítima deve necessariamente ser precedida por alguma acusação, ainda que não haja nenhuma que não a vaga "falta de afinidade". Para que se conquiste essa sofrida, mas incrivelmente concorrida, oportunidade de levar alguém à beira da aniquilação, que é idêntica à de ser escolhido para o mesmo fim, é necessária uma pré-pré-seleção: a entrevista para o ingresso no Big Brother, nomeada por seus produtores como "cadeira elétrica”. Os participantes, então, se livram do eletrochoque, são obrigados à confissão para serem, finalmente, encaminhados ao fuzilamento. Ou, como afirmou Theodor Adorno, a respeito da narrativa kafkiana: "o nexo imanente se concretiza como uma fuga de prisões" em que se "pula de uma situação desesperadora e sem saída para outra"².

A seleção já não é apenas o ritual de entrada no mercado de trabalho, como poderia supor o colarinho-branco de Wright Mills. Em um mundo no qual o mercado é soberano e aniquilador, o "mecanismo de seleção" que o define passou ao centro das relações sociais. Visto que "praticamente todos os trabalhadores converteram-se em membros intermitentes/latentes pela permanente desqualificação e pela informalização"22, "entrada" e "saída" tornaram-se estado contínuo e contíguo. Por isso não é possível nos determos em uma banca de jornal sem depararmos com o sempre novo e sempre igual manual para processos seletivos: devemos falar assim e vestir assado, ou falar assado e vestir assim, mas sempre devemos. Essa compulsão midiática infla o fantasma da eliminação ao mesmo tempo que aponta para um sintoma: a elevadíssima rotatividade da força de trabalho faz com que se encare o crivo do mercado inúmeras vezes ao longo da vida ${ }^{23}$. Contudo, se a triagem de "fora para dentro" se propaga é apenas porque ninguém pode ou deve permanecer. A voz de comando da flexibilidade faz com que as empresas incorporem os procedimentos seletivos em seu funcionamento regular, se é que a deriva do trabalho sob os mais variados tipos de contratos precários pode ser chamada regularidade. O estágio é a forma pela qual o amálgama entre a exceção e a norma aparece com maior clareza. Nele, o trabalho realizado é, ao mesmo tempo, uma prova, mediante a qual o novato pode ou não ser efetivado. Mas não é somente nesses inúmeros interstícios da precariedade que a seleção se torna permanente. Mesmo aqueles que logram o almejado emprego não estão livres da peneira. A "avaliação de desempenho" é um dispositivo da gestão flexível que funciona como uma espécie de seleção “de dentro para fora”. Ela é apresentada pela parolagem gerencialista como "uma discussão franca e aberta”, na qual o empregado pode "exprimir-se livre e objetivamente", sem medo de represálias, quase que como em um "confessionário". De fato, trata-se de uma "prática ideológica e um dispositivo de sujeição”24 que, mediante notas, gráficos, rankings e até conselhos, materializa o risco do descarte. $\mathrm{O}$ procedimento torna-se a prova empírica, palpável e sofrida, da situação vulnerável na qual se encontram também aqueles que estão "dentro". As avaliações se alastram sob formas variadas - como entrevistas, relatórios, testes, questionários, autoavaliações e até

2I ADORNO, Theodor W. Anotações sobre Kafka. In: Prismas: Crítica Cultural e Sociedade. São Paulo,

Ática, I998, p. 263

22 OLIVEIRA, Francisco de, op. cit., p. I8.

23 BERNARDO, João, op. cit.

24 BONETTI, Michel; DESCENDRE, Daniel; GAULEJAC, Vincent de; PAGĖS, Max. O Poder das Organizações. São Paulo, Atlas, 2008, p. IOO-IO2. 
gincanas imbecis e vexatórias que, assim como nos processos de admissão, são nomeadas “dinâmicas"- e aparecem nos mais diversos momentos, podendo ser ordinárias ou extraordinárias, estar em reuniões ou ocorrerem ao lado da máquina de café. Segundo um de seus incontáveis entusiastas, há "dois tipos de avaliação: a avaliação formal, que ainda é usualmente feita uma vez ao ano, sendo conduzida como parte da política da organização, e a avaliação rotineira ou informal"25. A avaliação onipresente faz com que o contratado deva provar incessantemente ser merecedor do privilégio que é seu emprego, assim como o faz o aspirante ao mesmo privilégio. Nessa porta giratória infinita, a entrada e a saída são faces de um mesmo processo, entre elas está o vidro de uma seleção tornada permanente.

Por isso, não é por obra e graça da criatividade de produtores de TV que os espetáculos da realidade são, grande parte, processos seletivos televisionados. Se o Big Brother acena para seus participantes, temporários da fama, com a possibilidade de conquista da estabilidade profissional na indústria cultural, há todo um subgênero que oferece abertamente o emprego para aquele que lograr fugir às eliminações. Em America's next top modele ${ }^{26}$ o prêmio para a moça que resistir às provações, mas jamais a sua obrigatoriedade, é um contrato com a empresa Elite Management e com uma marca de cosméticos; em O Aprendiz ${ }^{27}$, é oferecido um emprego de um ano como executivo na empresa do apresentador que estiver no comando do show; em Por um fio ${ }^{28}$, no qual concorrem cabeleireiros, o vencedor deve realizar um editorial para uma revista feminina; Hell's Kitchen ${ }^{29}$, um programa no qual os participantes devem cozinhar sob todas as formas de assédio moral imagináveis, agracia o sobrevivente com a vaga de chef executivo em um restaurante diferente a cada edição. A remuneração-prêmio, ofertada como contrapartida pela labuta televisionada, é a mesma que aquela prometida a estagiários: mais trabalho! Pois, da perspectiva do descarte, o emprego não é apenas um favor do capital, mas também o sonho de consumo do trabalho, pelo qual há que se "lutar"em outros termos, há que se aproveitar ao máximo cada "oportunidade" oferecida, melhor dizendo, e assim dispensamos as aspas: há que se aceitar qualquer imposição. Estamos, assim, submetidos à circularidade insolúvel de trabalhar arduamente, e a qualquer preço, para conseguirmos permanecer trabalhando ou para "arrumar trabalho".

Não é por outro motivo que mesmo os programas que dispensam o descarte de gente entre seus procedimentos têm nele, igualmente, o pressuposto de sua existência. Em meio ao emaranhado de terceirizações, indiscerníveis a olho nu, e de todas as formas de trabalho privatizado e precário, a fronteira que antes divisava a empresa do resto do mundo aparece nublada. Contudo, longe de se ter rarefeito, sua imagem é onipresente, e o mundo

25 GUILLEN, Terry. Avaliação de Desempenho. São Paulo, Nobel, 2000, p. II.

26 Transmitido pelo canal a cabo Sony, esse formato também teve sua versão nacional realizada em três edições, a partir de 2007, pela mesma emissora.

27 Entre 2004 e 2009 o programa foi apresentado pelo empresário Roberto Justus, em 20Io passou a ser comandado por João Dória Jr. Todas as temporadas foram realizadas pela Rede Record. O original americano é apresentado e produzido pelo magnata Donald Trump; sua brutalidade, bem como seu bordão, "You're fired", foram adotados pelo similar nacional.

28 Transmitido pelo GNT, o programa teve sua temporada de estreia em 2010 e uma segunda em 2012.

29 O programa, que está em sua $\mathrm{I}^{\mathrm{a}}$ temporada, já foi transmitido no Brasil pelos canais LIV e GNT, atualmente pode ser assistido no TLC. 
a deve espelhar, se autovalorizando à espera da graça de se autovalorizar quando em seu regaço. Nos assim chamados "realities de transformação" o prêmio não é o emprego, mas o improvement necessário para que se o conquiste ou, de outro modo, que é o mesmo, para que se possa permanecer na corrida estacionária em escada rolante. No Esquadrão da moda, transmitido pelo SBT, amigos e familiares armam uma arapuca para que seu conhecido seja entregue nas mãos de dois especialistas em moda. Estes, após ministrarem algumas sessões de humilhação, acabam por "mudar radicalmente o visual" do "mal vestido". 0 procedimento é simples, não obstante doloroso, pois para que o participante não seja atirado na lata de lixo, suas roupas o são, literalmente. Em um segundo momento, dá-se início ao investimento-em-si - que jamais será para-si, pois apenas é-, e, longe do divertimento do consumo, é posta a maratona das compras heterônomas: obedientes às regras do casal fashionista, produtivas e voltadas para o upgrade necessário. A justificativa da intervenção é repetida à exaustão, daí a ocupação do selecionado estar sempre em primeiro plano no momento em que é convencido a participar. Se a vítima é professora, dizem que não será levada a sério por seus alunos a não ser que melhore sua aparência; se afirma que tem dois empregos, fica cansada e por isso busca conforto no vestir, a resposta da especialista é: "mas você sabe que o mercado é competitivo e você sabe que para se manter você precisa se dedicar, e sua imagem é uma dedicação que você tem que ter" "3 ; se é uma dona de casa "talvez esteja desempregada porque se veste mal" e uma voz em off complementa: "claro, estar bem vestida é o mínimo pedido em uma entrevista de emprego" ${ }^{31}$.

\section{IV}

O essencial para a administração não é que sejam eliminados justamente os mais inúteis e sim que surjam logo vagas numa porcentagem prefixada..$^{22}$

Primo Levi

Intuída com um arrepio, a triagem espreita, atenta à roupa inadequada, ao comportamento incorreto, ao relacionamento que não rende, ao corpo equivocado, às memórias das quais devemos nos livrar tendo em vista uma melhor adaptação. Para cada uma dessas angústias, e para quaisquer outras que esse mundo hostil possa forjar, os reality shows de transformação, bem como os de autoajuda33, oferecem suas recauchutagens. Entretanto, "ninguém jamais

30 Programa exibido no dia 3I mar. 20I0. Grifo meu.

3I Programa exibido no dia 24 ago. 2010.

32 LEVI, Primo. É Isso um Homem? Rio de Janeiro, Rocco, I988, p. I3I.

33 Nesses, um expert qualquer oferece sua consultoria ao participante; não obstante a multiplicidade infinita do aspecto a ser "endireitado", a lição é sempre a mesma: adaptação a um mundo dissolvente, não obstante, aliás, por isso mesmo, funcional. Para a "reeducação alimentar" há, por exemplo, o programa Você é o que você come (GNT), no qual a nutricionista analisa as fezes de sua vítima e depois dispõe, sobre a mesa de jantar, sacos plásticos cheios de gordura derretida; então afirma: "Isso é o que você come, você é o que você come”. No quesito apagamento do passado, o programa Chega de Bagunça (Discovery Home and 
está seguro”, garantem os manuais de gestão tanto quanto os apresentadores de reality shows. Daí o metro do certo, do bom, do apropriado ou, em termos próprios a nossa sociedade, daquilo que rende, não constar em nenhuma régua existente. Em America’s Next Top Model, muito mais que a capacidade da fotogenia, é exigida da participante a "personalidade" de uma top e isso não é nada fácil de determinar. A aspirante a modelo pode errar pelo desleixo de sua roupa tanto quanto pela postura escandalosa, mas se a roupa que usa é "uptight" ou a moça apresenta demasiada frieza ante a linha de aniquilação também corre o risco da expulsão. $\mathrm{Na}_{\text {II }}{ }^{\mathrm{a}}$ edição do programa, transmitido no Brasil em 20Io, uma das participantes foi descartada por apresentar muito autocontrole, afinal às vezes "não estar no controle é a coisa mais linda"34. A moça que então foi salva se safou por pouco, pois também ela apresentava um desvio de personalidade: não sabia se controlar e deixava transparecer seu nervosismo. Safou-se por pouco, mas por pouco tempo, pois já na semana seguinte foi expulsa por ter levado a sério o ensinamento anterior, e então sua personalidade se tornou "too flat" para o gosto da apresentadora-modelo-juíza-executora35. Em um programa semelhante que busca o Top Chef $^{36}$ é bastante comum que sejam eliminados os cozinheiros inseguros, mas houve um que, tendo apresentado muita "autoconfiança”, também foi defenestrado. Já em O Aprendiz, o festival de injunções paradoxais segue à risca as insanas diretrizes corporativas: pensar em si/pensar na equipe; comandar/obedecer; seguir regras/ romper regras; ser modesto/ser pretensioso; concorrer/cooperar etc. Se o cabeleireiro corta demais sai, se corta de menos sai, se o costureiro mostra demais sai, se mostra de menos sai, e se fica no meio do caminho não ousou o suficiente...

Se os critérios, nessa categoria de reality shows, são gelatinosos, e negam o princípio da qualificação profissional que, em tese, seria seu mote, em programas de confinamento, como o Big Brother, são pura fantasmagoria. Nesse caso, não cabe sequer a farsa dos experts, o juiz é “o povo", e seus desígnios são da ordem do imponderável. Sendo assim, alguns pecam por excesso de timidez, outros por serem “exagerados”. Há aqueles que são muito briguentos, mas, do mesmo modo, podem ser eliminados os considerados excessivamente amistosos; autoritários ou obedientes, jovens ou maduros, espertos ou ingênuos - grande parte da graça para os aficionados é descobrir o porquê da eliminação, mas o fato é que ninguém sabe quem será o próximo a ir para o ferro-velho da indústria cultural. Entretanto - e por mais surreal que possa parecer-, apesar do enigma da eliminação, os “confinados" não abrem mão de suas “estratégias de jogo”. São duas as principais: "ser vocêmesmo” ou “jogar”. Posturas às vezes postas

Health) recolhe os apegos materiais “desnecessários” que "atravancam a casa” e monta um bazar. Quanto aos relacionamentos, podemos contar com a disciplina de Supernanny (SBT), para o adestramento dos filhos, ou com o reality Ou Eu ou o Cachorro (GNT), voltado para outro objeto, mas com a mesma finalidade. Segundo uma reportagem que trata desses dois últimos programas, sua relevância está no fato de que, em um "mundo hipercompetitivo [...] cada vez mais, as regras capitalistas impõem-se com mais força sobre as relações profissionais, pessoais, afetivas. [...] Por que não oferecer a experiência dos vencedores a quem ainda não é?”. Atenção para o nome da matéria, realizada por Laura Capriglione e Ricardo Westin: Manuais de sobrevivência. Folha de S. Paulo, 3 ago. 2008.

34 "Not being in control is the most beautiful thing". Disponível em: 〈http://goo.gl/6Somjl〉. Acesso em: 20 abr. $20 I I$. 35 〈http://goo.gl/aBqQDd〉. Acesso em: 20 abr. 20II.

36 Programa americano transmitido pelo Sony, a edição aqui referida foi a sexta, transmitida no Brasil em 20II. 
como contraditórias e excludentes, já que na "vida real” as pessoas não estão “jogando”. Em outros momentos, no entanto, a "estratégia” é "ser você mesmo", pois isso seria um sinal de honestidade, a pessoa não estaria "simulando" algo que ela não é. Mas a honestidade pode estar justamente na postura oposta: a afirmação veemente de que aquilo é um jogo que deve ser jogado. Pouco importa, ao fim e ao cabo ninguém nega que se trata de um jogo, cada qual escolhe suas armas, e "elimina” o outro para não ser "eliminado”. O único pecado é "não jogar", não no sentido de "ser você mesmo", mas no sentido de não agir em prol da eliminação de alguém. Ainda na última edição do programa, o apresentador se mostrou preocupado com a "passividade" dos participantes diante do "jogo": "Vocês estão cruzando os braços, mas se há uma coisa exclusiva desta edição é que não há um favorito uma semana antes da final. Por isso, o que pode ser chamado de falta de combatividade pode ser fatal para a chance de vocês"37. Fatal para a chance de quem, se não há favorito? Tanto faz, o fundamental é combater, ir à luta, batalhar...

"Resta como resultado, então - disse K. - que tudo é obscuro e insolúvel, a não ser minha expulsão"38. Pois não é que a máquina de moer gente em que se converteu o mundo inteiro exista para excluir o pior, tampouco o melhor, são eles, qualquer um, todos, que assim são declarados para que seja cumprida a taxa de aniquilação previamente estabelecida. Toda seleção se converte em seleção negativa, sua finalidade não é a escolha, mas o movimento que ela mesma gera.

\section{V}

- Apertei a primeira alavanca - disse O’Brien. - Compreendes a construção desta gaiola. A máscara adapta-se à tua cabeça, sem deixar saída. Quando eu apertar esta outra alavanca, a porta da gaiola correrá. Os monstros famintos saltarão por ela como balas. Já viste um rato pular no ar? Pularão sobre teu rosto e começarão a devorá-lo.39

George Orwell

Conheçam o nosso “capacete dos infernos”. Vocês estarão algemados e com essa caixa de vidro na cabeça. Em quatro etapas, vamos colocar bichos dentro desse capacete de vidro e girá-los de cabeça pra baixo. Vocês vão poder escolher a ordem que vamos colocar esses bichos. Quais são esses bichos? Larvas, sapos, ratos e serpentes. Lembrando que as serpentes serão as últimas obrigatoriamente. $4^{\circ}$

Glenda Kozlowski

37 BIAL, Pedro. Não há favoritos. Disponível em <http://bbb.globo.com/BBB8/Noticias/o,,MUL3544I6-945I,00. html $>$. Acesso em: 20 maio 2009.

38 KAFKA, Franz. O Castelo. Trad. de Modesto Carone. São Paulo, Companhia das Letras, 2000, p. II5.

39 ORWELL, George. I984. Trad. de Wilson Veloso. I6. ed. São Paulo, Companhia Editora Nacional, I983, p. 207.

40 Glenda Kozlowski, apresentadora de Hipertensão, reality show levado ao ar pela TV Globo em 20Io. O programa é um apanhado de provas degradantes e perigosas, mediante as quais se vão eliminando aqueles que "não resistem". 
Graças à arbitrariedade, dita e sabida, desse falso jogo, a punição não estabelece relação de sentido ou consequência com qualquer forma de culpa, não obstante ser praticada ininterruptamente. Porém, precisamentepor ser prática incógnita, o suplício culpabiliza, impondo sua obrigatoriedade, sem que a isso corresponda expiação. Por isso, o caminho que leva aos incontáveis paredões deve ser pavimentado por pedras laminares - nada o diferenciando de seu destino. O conjunto do que alguns espetáculos da realidade chamam de "prova", outros de "desafio" e alguns de "tarefa" compõe a via-crúcis sem redenção que conforma os programas, tanto quanto a vida produtiva sob capitalismo flexível. Ao analisar os parâmetros para prêmios e punições, distribuídos pela "doença social" que é a gestão, Vincent de Gaulejac descobriu o mais puro “nonsense". Ele cita uma pesquisa, realizada em meio ao processo de reestruturação produtiva dos correios franceses, na qual se descobriu que "entre todas as componentes de sua atividade [do atendente], a única que é simbólica e financeiramente gratificada pela instituição é aquela cujo resultado parece ser o mais desligado da qualidade de sua ação particular”. Não a lógica, mas a "equação ilógica" "consiste em gratificar o ingratificável: o acaso", ou, em termos de uma funcionária que ganhou um prêmio, em suas palavras, "sem nada ter feito": "É mesmo uma pândega..."포 $\mathrm{A}$ brincadeira de mau gosto se deve à forma informe das regras que, na empresa contemporânea, "não são fixas, mas modificadas sem cessar, remodeladas, algumas desaparecem e outras começam a ser aplicadas"42 e nos reality shows, idem, ibidem.

As "provas", no Big Brother, determinam o papel que o participante ocupará no jogo ao longo de uma semana, quem será o "líder" ou "imunizado" ou "anjo" ou "monstro" ou qualquer coisa que o valha, ou que não o valha. Pois não é apenas a isso que se prestam, às vezes oferecem algum prêmio, mais frequentemente outro castigo, outras vezes determinam a qualidade e quantidade de alimentos que será oferecida aos confinados, há momentos em que determinam o espaço na casa que será ocupado por cada um, ocorre também que não se saiba de seu propósito, fora a possibilidade de a atividade não servir a absolutamente nada e ser apenas uma enganação. Quando a Lei é a expulsão e a vivência é sobrevivência não se pode falar em funcionamento regular; aquilo é o reino do capricho. Todas as regras do programa podem ser e, de fato, são alteradas, não a cada edição, mas a cada rodada, muitas vezes são trocadas no decorrer de alguma atividade ${ }^{43}$. Até mesmo a "formação do paredão" pode obedecer a tantas variações, na forma da indicação, na quantidade de "emparedados" e de eliminados, que seria cansativo enumerá-las. Por sinal, é possível que o "paredão" sequer seja formado, como no caso de pessoas levadas à desistência pela via da tortura. Também não se podem levar ao pé da letra as regras de entrada no programa, da tal "cadeira elétrica", já que os voluntários podem ser selecionados via inscrição, sorteio, participação em comunidades virtuais ou ser convidados por "olheiros".

4I GAULEJAC, Vincent de. Gestão como Doença Social: Ideologia, Poder Gerencialista e Fragmentação Social. Aparecida, Ideias \& Letras, 2007, p. I56.

42 BONETTI, Michel; DESCENDRE, Daniel; GAULEJAC, Vincent de.; PAGÈS, Max. op. cit., p. 49.

43 Exemplo: Há um reality americano que seleciona designers de moda chamado Runaway Project (transmitido no Brasil pelo canal a cabo LIV). Os concorrentes devem criar e costurar, em um dia, uma roupa para ir a julgamento. Em meio à produção, o apresentador irrompe no ateliê e aumenta o desafio: os designers devem produzir duas roupas no mesmo período de tempo. Esse exemplo é completamente aleatório, pois a mudança das regras com o jogo em andamento é constitutiva de todos os reality shows em que há competição. 
Houve uma vez em que, para conseguirem o passe para o aprisionamento, algumas pessoas ficaram uma semana expostas em uma casa de vidro dentro de um shopping para serem eleitas pelos consumidores que as consumiam ao vivo. Em outra ocasião, duas pessoas foram levadas ao programa no meio da disputa, quando outros já haviam saído. Em 20Io, um "ex-BBB" ressuscitou e voltou à casa, com todo o seu "acúmulo de experiência", e venceu. Em 20II, os eliminados das primeiras semanas foram parar na casa de vidro e um deles ressuscitou após o terceiro dia.

A sensação de injustiça é inevitável, mas parece pouco importar, pois todos compreendem que as exceções são a regra do jogo. Os participantes sabem que os martírios aos quais se submetem não obedecem a princípios, e sim a decretos estabelecidos ao sabor das vontades do soberano, tanto quanto sabem que suas chances de vitória, mais que mínimas, são fortuitas. Ainda assim, não há um pestanejar entre a ordem que surge de uma voz descarnada qualquer - pelo telefone do Big Brother, por uma tela de computador, em America's next top model, ou como vinda dos céus, em Solitários ${ }^{44}$ - e sua execução. Num átimo, se deixam levar a um "quarto branco", no qual sofrem privação sensorial45; passam cinco horas em pé sobre troncos estreitos e sob sol cearense ${ }^{46}$ ou dobrados em carros e

44 Nesse programa, produzido pelo SBT, os participantes são confinados isoladamente uns dos outros, só tendo acesso a uma voz eletrônica que lhes transmite a forma de tortura a qual serão submetidos. Aquele que resistir por mais tempo, vence.

45 Trata-se de uma prova levada a cabo na edição de 2009. Na descrição presente no site da emissora, tratava-se de "um quarto simples, austero, com poucos móveis. Relativamente pequeno. Bem no meio, um pedestal com um botão e uma luz rotativa com alarme. Três camas, um gaveteiro, um frigobar e um pequeno banheiro. As paredes todas revestidas por um almofadado branco. O piso, também branco. E as camas também. Aliás, com exceção da lâmpada e do botão [ambos vermelhos], tudo no quarto é de um branco ascético, com iluminação ofuscante". Retrospectiva: o Quarto Branco. Globo.com - Big Brother Brasil, 7 abr. 2009. Disponível em: 〈http://goo.gl/z7PzA2〉. Acesso em: I7 maio 2009. "Relativamente pequeno" fica por conta das Organizações Globo. Tratava-se de um quarto de $2 \mathrm{~m} \times 2 \mathrm{~m}$ sem janelas. As paredes acolchoadas como em manicômios, prestavam-se ao duplo objetivo de isolar qualquer barulho externo e deixar os participantes aturdidos com sua textura, como afirmou um dos infelizes que lá ficou trancafiado.

46 "Prova" da quarta edição de No limite. Versão brasileira do sucesso americano Survivor e transmitido pela Rede Globo de 2000 a 20Io, o programa atira seus protagonistas em "paraísos selvagens", como afirma sua propaganda, nos quais, longe de serem deixados à deriva - afinal, quem carregaria a câmera? - são permanentemente atormentados por provações físicas e privações diversas. Como que para mostrar de onde vem a real selvageria, o site da emissora descreve a "dinâmica" do "jogo": "Uma verdadeira luta pela sobrevivência, repleta de obstáculos, vai testar a resistência dos participantes do programa. Para vencer, é preciso estar preparado para enfrentar uma rotina intensa, cheia de provas e desafios que podem render diversos prêmios. Toda segunda-feira, os guerreiros disputam provas para conquistar itens que facilitam a sobrevivência no paraíso selvagem. Já imaginou a falta que faz uma caixa de fósforos? Às terças-feiras, as tribos lutam pela imunidade. Quarta-feira é dia de descanso e, quem sabe, festa ou passeio na selva para uma das tribos. Tudo para que, na quinta-feira, os guerreiros possam enfrentar o Portal, ao vivo. Após a eliminação, sexta-feira é dia de conquistar mais itens de sobrevivência e também de preparação para a prova de sábado, que define quem está imune ao Portal de domingo, quando mais um participante é eliminado, encerrando a semana. Eventualmente, os integrantes de cada tribo podem ter que votar entre si para mandar um ou mais participantes para o Exílio. Durante 24 horas, o escolhido deverá ficar isolado do grupo, em 
casinhas de cachorro ${ }^{47}$; têm suas roupas atiradas no lixo ou seus cabelos $\operatorname{cortados}^{48}$; se oferecem à humilhação ao terem os corpos expostos em gaiola de vidro, no meio da rua ${ }^{49}$, ao terem que se fantasiar de galinha e cacarejar cada vez que um sinal toca, ao terem que se fantasiar de esponja e rebolar enquanto detergente líquido cai sobre suas cabeças, ao terem que se fantasiar de frango assado e entrar em um imenso forno escaldante ${ }^{50}$; se submetem à privação de sono ${ }^{5 \mathrm{I}} \mathrm{e}$ ao frio - o desconforto climático foi uma das "inovações" do Big Brother Brasil atualmente transmitido:

Uma das novidades de Big Brother Brasil I4 será um quarto 'gelado' [vai entender o porquê das aspas...], com temperatura máxima de I8 graus durante o dia. $\mathrm{O}$ ambiente foi batizado pela produção de Sibéria. [...] Sibéria abrigará participantes punidos pelo programa. No local, eles não poderão usar agasalhos nem tomar banho quente. À noite, a temperatura irá cair, promete o diretor-geral do reality show, J. B. Oliveira, o Boninho. Segundo o site oficial de BBB I4, irão para a Sibéria os perdedores da Prova da Comida. Ou seja, ao invés da Xepa (comida racionada), os novos 'brothers' vão passar frio..$^{22}$

um local afastado." ISOLAMENTO. Globo.com - No Limite. Disponível em: 〈http://goo.gl/WLerGV〉. Acesso em: I3 fev.20I4.

47 Esse tipo de "desafio" é praxe em muitos reality shows, no BBB, por exemplo, o curvar-se em carro - esse sempre com o logotipo sublinhado pela câmera - é o trote de entrada dos participantes na casa. O recorde das assim chamadas "provas de resistência" ocorreu no BBB I2, no qual duas moças passaram 25 horas e meia trancadas no carro patrocinador.

48 No supracitado Esquadrão da moda, as lágrimas correm ocasionalmente quando as roupas são descartadas, mas são praticamente inevitáveis quando é chegada a hora da tosa: todas as participantes, independentemente do visual a ser socialmente retificado, têm seus cabelos cortados - nesse momento, as súplicas daquelas que têm demasiado apego a suas madeixas, são também em vão. Contudo, não é necessário que sejam algemadas à cadeira do cabeleireiro, no geral, basta o imperativo da "renovação" para que o sacrifício seja executado. $\mathrm{O}$ mesmo comando leva pessoas a se submeterem a mutilações mais dolorosas: Extreme Makeover, o mais famoso entre os realities de transformação, realizava toda sorte de cirurgias plásticas a um só tempo - todas minuciosamente registradas em cenas explícitas de sucções, incisões, sangramentos, colocação de próteses etc.

49 Em Dez anos mais jovem, outro reality de transformação do SBT, a candidata ao improvement estético é levada a uma cabine de vidro, disposta na calçada de uma avenida qualquer, onde tem sua imagem espinafrada por transeuntes; ao cabo da via-crúcis, que vai do peeling à troca de dentição, o espécime vivo retorna à vitrine na qual a eficácia do método é invariavelmente comprovada.

50 O primeiro desses três eventos ocorreu no Big Brother Brasil 9, o segundo na Io ${ }^{a}$ edição, com patrocínio dos caldos Knorr, e o terceiro na II ${ }^{\mathrm{a}}$, patrocinado pela marca de produtos de limpeza Minuano. O primeiro foi um "castigo" dado por um telefonema, os outros dois foram "provas de liderança", mas tanto faz, a prova é sempre também uma punição e vice-versa.

5 Em Solitários, além do isolamento, das provas cruéis e da privação sensorial promovida pela própria cela, os cativos têm o sono interrompido por músicas tocadas aleatoriamente.

52 Big Brother I4 Terá “Sibéria”, Sala “Gelada” para Punir Participantes. Notícias da TV, I4 jan. 20I4. Disponível em: 〈http://goo.gl/LYGgCd〉. Acesso em:I3 fev. 20I4. (Grifo meu.) 
Não que a imposição do desconforto térmico em si seja novidade, o mesmo programa já enfiou participantes em uma garagem na qual ficaram submetidos a variações climáticas abruptas - frio, calor, chuva e vento - determinadas mediante votação de telespectadores internautas. Por fim (da presente enumeração, não dos tormentos), é imposta aos participantes toda sorte de disrupção alimentar, ocorrência quase natural nessa espécie de entretenimento: praticamente todos os programas impõem aos participantes a fome, o racionamento, ou a ingestão de alimentos, digamos, socialmente interditos - e aqui voltamos à exemplificação no rodapé, para poupar, ao leitor ainda sensível à barbárie, a náusea ${ }^{53}$.

\section{VI}

Para ele, a atitude de cumprimento preciso da ordem é mais importante que o conteúdo das ordens, e mais importante que a moralidade dos que ordenam..$^{54}$

Günther Anders

Apontar a crueldade dos reality shows seria um exercício fútil não fosse a completa ausência de estranhamento - para não dizer horror - da sociedade que os produz e consome. A violência vã exibida todos os dias em tais programas não é um princípio subjacente, cujo desvelar demandaria algum esforço reflexivo. Pelo contrário, da bestialidade da criatura se faz propaganda a cada chamada no intervalo comercial: "O cerco fecha, o medo aumenta..."55; os

53 De Solitários: "Para ganhar o direito de comer, eles tiveram que adivinhar quantas calorias havia naquela refeição. E já dá para imaginar o que aconteceu, não é? Teve gente que comeu só com os olhos... Sim, a número 5 foi tão mal que não teve direito de tocar em nada”. E a Cabine 4 Tem um Novo Dono!, SBT - [SOLITÁRIOS] $2^{a}$ Temporada. Disponível em: 〈http://goo.gl/OaBXv5〉. Acesso em: II fev. 20I4. De No Limite: "Na I fase, cada membro de cada tribo comeria 2 olhos de cabra cada. $\mathrm{Na} 2^{\mathrm{a}}$ fase, 4 pessoas de cada tribo deveriam comer 3 peixes pequenos vivos”. No Limite 4. Wikipédia. Disponível em: 〈http://goo.gl/2bVoUO〉. Acesso em: I3 fev. 20I4. De Hipertensão: "A prova 'lojinha de horrores' desafiou o estômago dos três participantes na berlinda, dessa vez, obrigados a comer ratinhos, baratas e gafanhotos - estes últimos, vivos!”. Enquete: Qual Foi a Prova Mais Radical? Globo.com - Hipertensão, I8 out 20Io. Disponível em: 〈http://goo.gl/Vbcq3s〉. Acesso em: I9 ago. 20II. Ainda Hipertensão: "Diante da tarefa de um candidato, obrigado a beber uma mistura de vermes, fígado e óleo, tudo batido no liquidificador, Glenda [Koslowsky, apresentadora] orientou: 'Se tiver ânsia de vômito, pode vomitar dentro do copo e continuar bebendo. Se vomitar fora, está eliminado'” Stycer, Maurício. As Dez Piores Atrações da Televisão em 20Io: Uma Retrospectiva. Blog do Maurício Stycer, I5 dez. 20Io. Disponível em: 〈http://goo.gl/ZwoxXV〉. Acesso em: 20 dez. 2010.

54 ANDERS, Günther. Kafka: Pró \& Contra. São Paulo, Cossac Naify, 2007, p. Io5.

55 Chamada para o programa A Fazenda, veiculado pela TV Record em 20I3. Esse reality é produto similar ao mais famoso Big Brother Brasil. Assim como ele, trata-se do isolamento de aproximadamente uma dúzia de pessoas em uma casa, da qual são eliminadas uma a uma, mediante voto do público. A diferença entre 
produtores e apresentadores exibem, com o orgulho dos fortes, o caráter da coisa: "É horrível, você sabe que é uma morte para a pessoa. Acabou, acabou toda uma vida, uma história, um grande sonho, acabaram esperanças" ${ }^{36}$; e não há vestígio de embaraço diante do que se pretende promover: "Fome, frio, calor, desconforto e precariedade colocam em xeque a sanidade mental dessas pobres cobaias" ${ }^{7}$, longe disso, o crime a ser perpetrado não passa de objeto de escárnio para o carrasco: "Daqui a pouco tem votação para mandar três novas ovelhas para o sacrifício"s8. Nesse caso, pode-se dizer, sem titubear, que o produto está à altura de sua propaganda.

À questão que se segue, ou deveria se seguir: “então porque participam?”, o cinismo brutal oferece a pista: de fato, trata-se de sacrifício, de sacrifício ritual. Mais do que isso, a exaustiva ratificação da imanência é combustível para o tipo de cerimonial que assistimos na TV e vivenciamos em nossa reprodução social. Pois a vida submetida ao capitalismo flexível se converteu em um cada um por si desprovido do Deus por todos. Nos termos de Günther Anders, em sua análise da obra de Kafka, estamos diante de um ritualismo sem ritual que, longe de negar a religiosidade, toca seu núcleo original: a exatidão, da qual ainda guarda vestígio o termo "religiosamente”. Segundo ele, Kafka apresenta a precisão, o compromisso e o escrúpulo próprios dos rituais primitivos, porém desprovidos de conteúdo, "flutuantes". Os personagens de Kafka não sabem o que deve ser feito, mas fazem-no meticulosamente: "Seu monstruoso imperativo categórico poderia ser assim formulado: Cumpra com precisão os deveres que não conhece!" 59 Os protagonistas de reality shows, do mesmo modo, cumprem as missões transmitidas pelo acaso, por mais dolorosas e absurdas que sejam. Seu "compromisso com o jogo" não pode ser explicado pela adequação entre meios e fins, pois o cálculo resvala no que os participantes sabem não saber. Apesar disso, mais que cumprir a ordem da "combatividade", fazem-no com a precisão dos compulsivos, o zelo dos apaixonados. O mesmo imperativo pode ser lido através das palavras ocas de nosso “educador corporativo”: para ele, heróiépersonagem kafkiano. Os mártires da sobrevida sem transcendência ajoelham sem fé: erguem os braços em palestras motivacionais, colecionam pontos para currículos virtuais, cantam e sapateiam em processos seletivos, realizam relatórios sobre relatórios sobre relatórios sobre a avaliação do nada, passam horas em pé, em círculo, segurando cordinhas que os ligam uns aos outros, e o fazem não obstante saberem que a "prova" não passa de palhaçada ${ }^{60}$ - como, de resto, sabem todos os demais. Todos eles, todos nós, estamos simplesmente correndo atrás, melhor dizendo, fugindo da eliminação aleatória cuja respiração sentimos na nuca: movimento incessante e

as duas produções é de cenário: uma fazenda ao invés de uma casa, e de status: os participantes não são “pessoas comuns”, mas “celebridades”.

56 Pedro Bial, apresentador do $B B B$, em entrevista ao programa Encontro com Fátima Bernardes, transmitido no dia I4 jan. 20I4.

57 Texto de apresentação do programa Solitários, disponível no site da emissora: 〈http://goo.gl/xSUjuY〉. Acesso em: 30 jan. 20I4.

58 De novo, Bial, ao anunciar o "paredão" do dia 20 de Janeiro de 2014.

59 ANDERS, Günther, op. cit., p. I04.

60 Refiro-me aqui a uma prova-enganação, realizada no $B B B$, antes da "prova de resistência", cujo intuito era apenas enganá-los. Enquanto permaneciam nessa posição, comentavam: "Isso não é a prova ainda”, "Eles falaram que quem sair não pode comer. Então é porque vai ter outra coisa de noite”. 〈http://goo.gl/McCGuw〉. Aceso em Io de junho de 2010. 
afastamento do risco como um mesmo gesto, o único possível. Pois o perigo agnóstico não está na face do demônio, mas em sua ausência, na indeterminação da ordem inquestionável produzida pelo próprio sistema. O escrúpulo ritualístico se desdobra como proteção contra essa mesma “máquina de precisão". Por isso, a 'precisão' tem, hoje em dia, um significado de dois gumes: designa tanto o tipo de função do mundo perigoso como a salvação diante dele. Ela é, até certo ponto, homeopática: espera-se a cura exatamente do veneno contra o qual é tomado"rr. Resta a fantasmagoria de um automatismo que só permite "auto-humilhação e desespero"62.

Uma "religião compacta e encouraçada"63, a própria definição do capitalismo, ao menos para Walter Benjamin, que em suas notas a respeito do "Capitalismo como Religião"64 enxergou uma "religião puramente cultual, talvez a mais extrema que jamais tenha existido. Nada há nele senão uma relação imediata com o significado do culto; ele não conhece nenhum dogma especial nem teologia”. Pois o capitalismo, em si mesmo, absurdo -“o ser humano em função do ganho como finalidade da vida, não mais o ganho como meio destinado a satisfazer suas necessidades materiais. Essa inversão da ordem 'natural' das coisas, totalmente sem sentido para a sensibilidade ingênua, étão manifestamente e sem reservas um Leitmotiv do capitalismo, quanto é estranha a quem não foi tocado por seu bafo" ${ }^{5}$ - já há muito vem se despindo de qualquer espírito. Hoje, quando a empresa exige que seus colaboradores esfolem filhotes de gatos para tornarem-se dignos da permanência ${ }^{66}$, e estes cumprem, não obstante o que pensem a respeito, não obstante a resistência que seu próprio juízo possa oferecer, nada mais fazem que acatar a ordem de nosso modo de produção, finalidade sem fim. Como partículas minúsculas, movidas por forças mecânicas da natureza, já demos resposta à indagação formulada por Max Weber no início do século passado: "ninguém sabe ainda quem no futuro vai viver sob essa crosta e, se ao cabo desse desenvolvimento monstro há de surgir profetas inteiramente novos ou um vigoroso renascer de velhas ideias e antigos ideais ou - se nem uma coisa nem outra - o que vai restar não será uma petrificação mecanizada" 6 . A esfinge ainda aguarda a pergunta certa.

6I ANDERS, Günther, op. cit., p. IO7.

62 Idem, p. I05.

63 Idem, p. I03.

64 Devo a relação entre os resultados de minha pesquisa e o texto de Benjamin, que eu não conhecia, a Paulo Eduardo Arantes que, em sua leitura cuidadosa, levou meu trabalho ao bem vindo limiar da profanação. BENJAMIN, Walter. Capitalismo como Religião. Trad. de Jander de Melo Marques Araújo. Revista Garrafa, n. 23, jan.-abr. 20II. Disponível em: 〈http://goo.gl/ttHmUx〉. Acesso em: I7 mar. 20I4.

65 WEBER, Max. A Ética Protestante e o “Espírito" do Capitalismo. São Paulo, Companhia das Letras, 2004, p. 46-47. 66 O caso foi registrado por Christophe Dejours e relatado em entrevista: "Posso contar, por exemplo, o caso de um estágio de formação na França em que, no início, cada um dos I5 participantes, todos eles quadros superiores, recebeu um gatinho. O estágio durou uma semana e, durante essa semana, cada participante tinha de tomar conta do seu gatinho. Como é óbvio, as pessoas afeiçoaram-se ao seu gato, cada um falava do seu gato durante as reuniões, etc. E, no fim do estágio, o diretor do estágio deu a todos a ordem de... matar o seu gato”. DEJOURS, Cristophe. Um Suicídio no Trabalho é Uma Mensagem Brutal - Entrevista concedida a Ana Gerschenfeld. Jornal Público 2, I fev. 20Io. Disponível em: 〈http://goo.gl/f78kVd〉. Acesso em: I7 mar. 2014 . 67 WEBER, Max. op.cit., p. I66. 


\section{SOBRE A AUTORA}

SILVIa Viana Professora do Departamento de Fundamentos Sociais e Jurídicos da Escola de Administração de Empresas de São Paulo da Fundação Getúlio Vargas (EAESP-FGV). Doutora pelo Departamento de Sociologia da Faculdade de Fliosofia, Letras e Ciências Humanas da Universidade de São Paulo (FFLCH-USP). Autora do livro Rituais de Sofrimento (São Paulo, Boitempo, 20I2). Participa do conselho editorial da Revista Forma-mercadoria e é autora colaboradora do Blog da Boitempo.

E-mail: silvianarodrigues@gmail.com

\section{REFERÊNCIAS BIBLIOGRÁFICAS}

“'Big Brother' não é cultura, é um jogo cruel”, diz Boninho. Folha de S. Paulo, 2I mar. 2010.

"Not being in control is the most beautiful thing" Disponível em 〈http://goo.gl/6Somjl〉. Acesso em: 20 de abril de $20 I I$

ADORNO, Theodor W. Anotações sobre Kafka. In: . Prismas: Crítica Cultural e Sociedade. São Paulo, Ática, I998.

. Minima Moralia. São Paulo, Ática, I992.

ANDERS, Günther. Kafka: Pró \& Contra. São Paulo, Cossac Naify, 2007.

ARANTES, Paulo. A fratura brasileira do mundo. In: .Zero à Esquerda. São Paulo, Conrad, 2004 . . O pensamento único e o marxista distraído. In: .Zero à Esquerda. São Paulo, Conrad, 2004.

BARROS, Isabela; CAVALCANTI, Luciana. Só os Flexíveis Sobrevivem - entrevista com Claudia Rieken. Você S/A, ed. I04, Io fev. 2007.

BENJAMIN, Walter. Capitalismo como Religia. Trad. de Jander de Melo Marques Araújo. Revista Garrafa, n. 23, jan.-abr. 20II. Disponível em: 〈http://goo.gl/ttHmUx>. Acesso em: I7 mar. 20I4.

BERNARDO, João. Trabalhadores: Classe ou Fragmentos? Disponível em: <http://goo.gl/Jdwgbo〉. Acesso em: 20 abr. $201 \mathrm{II}$.

BIG BROTHER I4. Big Brother I4 Terá “Sibéria”, Sala “Gelada” para Punir Participantes. Notícias da TV, I4 jan. 20I4. Disponível em: 〈http://goo.gl/LYGgCd〉. Acesso em: I3 fev. 2014.

BONETTI, Michel; Descendre, Daniel; Gaulejac, Vincent de \& Pagès, Max. O Poder das Organizações. São Paulo, Atlas, 2008.

CAPRIGLIONE, Laura \& WESTIN, Ricardo. Manuais de Sobrevivência. Folha de S. Paulo, 3 ago. 2008.

COUTINHO, Laerte, Esfinge. Piauí, n. 5, fev. 2007. Disponível em: 〈http://goo.gl/KGyHVh〉. Acesso em: I2 dez. 2014 .

CASTRO, Eduardo. A morte como quase acontecimento. Conferência proferida na CPFL, Campinas, 2008. Disponível em: 〈http://goo.gl/QFasUK〉. Acesso em: I6 ago. $20 I I$.

DEJOURS, Cristophe. Um Suicídio no Trabalho é Uma Mensagem Brutal - Entrevista concedida a Ana Gerschenfeld. Jornal Público 2, I fev. 20Io. Disponível em: 〈http://goo.gl/f78kVd 〉. Acesso em:I7 mar. 20I4. GAULEJAC, Vincent de. Gestão como Doença Social: Ideologia, Poder Gerencialista e Fragmentação Social. Aparecida, Ideias \& Letras, 2007. 
GLOBO.COM. Enquete: Qual Foi a Prova Mais Radical? - Hipertensão, I8 out 20Io. Disponível em: <http://goo. $\mathrm{gl} / \mathrm{Vbcq3s}>$. Acesso em: I9 ago. $20 \mathrm{II}$.

. Isolamento - No Limite. Disponível em: 〈http://goo.gl/WLerGV >. Acesso em: I3 fev.20I4. . Retrospectiva: o Quarto Branco - Big Brother Brasil, 7 abr. 2009. Disponível em: 〈http://goo.gl/z7PzA2〉. Acesso em: I7 maio 2009.

GUILLEN, Terry. Avaliação de Desempenho. São Paulo, Nobel, 2000.

KAFKA, Franz. O Castelo. Trad. de Modesto Carone. São Paulo, Companhia das Letras, 2000.

LEVI, Primo. É Isso um Homem? Rio de Janeiro, Rocco, I988.

LÓPEZ-Ruiz, Oswaldo Javier. O Ethos dos Executivos das Transnacionais e o Espírito do Capitalismo. Tese de Doutorado em Sociologia, Campinas, Unicamp, 2004.

MANO, Cristiane. Chega de Ser Boazinha. Exame, ano 44, n. 20, 3 nov. 2010.

MUSSAK, Eugênio. Está na Hora de Mudar. Você S/A, n. II6, I fev. 2008.

. Evoluir é Fundamental para Sobreviver na Carreira. Você S/A, n. I79, I jan. 2013.

. Mensagem aos Acomodados. Você S/A, n. I54, I abr. $201 \mathrm{II}$

Quando Eu quase Desisti. Você S/A, n. I6o, I out. $20 I I$.

NO LIMITE 4. Wikipédia. Disponível em: 〈http://goo.gl/2bVoUO〉. Acesso em: I3 fev. 2014.

OLIVEIRA, Francisco de. Passagem na Neblina. In:___ _; Genoino, José \& Stedile, João Pedro. Classes Sociais em Mudança e a Luta pelo Socialismo. Coleção Socialismo Em Discussão. São Paulo, Fundação Perseu Abramo, 2000.

ORWELL, George. 1984. Trad. de Wilson Veloso. São Paulo, Companhia Editora Nacional, I982.

ROSSO, Sadi Dal. Mais Trabalho! A Intensificação do Labor na Sociedade Contemporânea. São Paulo, Boitempo, 2008.

SOLITÁRIOS. $2^{a}$ Temporada:. Disponível em: 〈http://goo.gl/xSUjuY〉. Acesso em: 30 jan. 2014.

SOLITÁRIOS. $2^{a}$ Temporada: E a Cabine 4 Tem um Novo Dono!, SBT. Disponível em: 〈http://goo.gl/OaBXv5〉. Acesso em: II fev. 20I4.

STYCER, Maurício. As Dez Piores Atrações da Televisão em 20Io: Uma Retrospectiva. Blog do Maurício Stycer, I5 dez. 20Io. Disponível em: 〈http://goo.gl/ZwoxXV〉. Acesso em: 20 dez. 2010.

WEBER, Max. A Ética Protestante e o "Espírito" do Capitalismo. São Paulo, Companhia das Letras, 2004. 